\title{
Evaluation of Microstructure and Mechanical Properties in Dissimilar Joint of SSM7075 with SSM356 Aluminum Alloy using Diffusion Bonding
}

\author{
Yongyuth Dunyakul $^{1, a, *}$, Chaiyoot Meengam ${ }^{2, b}$, Dech Maunkhaw ${ }^{1}$, \\ and Suppachai Chainarong ${ }^{2}$ \\ 1 Department of Industrial Engineering, Faculty of Engineering, Rajamangala University of Technology \\ Srivijaya, Songkhla 90000, Thailand \\ 2 Department of Engineering, Faculty of Industrial Technology, Songkhla Rajabhat University, Songkhla \\ 90000, Thailand. \\ E-mail: aDyongyuth@gmail.com (Corresponding author), bChaiyoot.me@skru.ac.th
}

\begin{abstract}
The aim of this study is to investigate joining parameters that affect microstructure and mechanical properties of diffusion bonding technique in dissimilar joints between SSM7075 and SSM356 aluminum alloys. Diffusion bonding methods were investigated by joining parameters as follows: contact pressure at $3 \mathrm{MPa}$, holding time 60 and 120 minutes and temperature at 673, 723, 773 and $823 \mathrm{~K}$ respectively, under argon atmosphere at 4 liters per minute. After experiments, the results of the investigation have shown that a condition used contact pressure at $3 \mathrm{MPa}$, holding time 120 minutes, and temperature at $773 \mathrm{~K}$ is complete and no defects and voids. Examination of the joint region using SEM and EDX showed that the microstructure in weld zone after welding is globular structure, and eutectics phases of two materials diffuse together. In weld zone, it was found that formation of eutectic phases has $\mathrm{Al}_{2} \mathrm{CuMg}, \mathrm{Mg}_{2} \mathrm{Si}$ and $\mathrm{Al}_{2} \mathrm{Mg}_{2} \mathrm{Zn}_{3}$ phases along the bond interface, distributed throughout bond interface. The tensile tested showed the maximum tensile strength of $94.94 \mathrm{MPa}$. The hardness was tested for optimum hardness value, 121.20 HV. However, the heat during welding, resulting in precipitation within the aluminum matrix $(\alpha-\mathrm{Al})$, led to increased hardness after diffusion bonding.
\end{abstract}

Keywords: SSM7075 aluminum alloys, SSM356 aluminum alloys, diffusion bonding.

ENGINEERING JOURNAL Volume 20 Issue 3

Received 9 September 2015

Accepted 2 December 2015

Published 19 August 2016

Online at http://www.engj.org/

DOI:10.4186/ej.2016.20.3.135 


\section{Introduction}

During many past years, the demand for materials in automotive industries, aerospace industries, and electronics industries increased ongoing; therefore, the development of materials for suitable applications is necessary. Many methods have been invented to enhance the properties of the material. Semi-solid Metal (SSM) casting is another way to increase the mechanical properties of the material with structural improvements [1]. It is a new technology and popularly used in many industries. Aluminum alloy is another material is formed with semi-solid casting techniques such as series $7 X X X, 6 X X X, 2 X X X$ and $3 X X$ aluminum alloy [2-4]. For welding of these aluminum together, it is not easy especially those welding between two different materials. The liquid-state-welding techniques of different materials are also much more difficult because their chemical properties are different and lead to the formation of porosities, solidification cracking, microstructure changes in welded zone, and other welding defects. Selecting an appropriate welding method for welding different materials to solve these problems is important. Solidstate-welding techniques are interesting as researchers have recently found these new techniques appropriate for welding different materials. Typically, there also have many successful methods, such as friction stir welding [6], friction welding [7], and diffusion bonding [8-10]. Among these welding techniques, the diffusion bonding technique is interesting because it has been widely used to produce reliable interfaces between similar and dissimilar materials. It relies on the diffusion of atoms to material bonded together. Diffusion bonding (DB) is a solid state joining process by which two nominally flat interfaces can be joined at an elevated temperature using an applied pressure for a time ranging from a few minutes to longer. This diffusion bonding technique is popularly used in producing main fuel tank for aircraft because no porosity can be observed after welding. The temperature is usually in the range of 0.5$0.8 \mathrm{Tm}$, where $\mathrm{Tm}$ is the absolute melting point of the material being joined [11]. The main parameters for diffusion bonding are holding time, temperature, contact pressure, and preparation surface. Although the welding of aluminum alloy by diffusion bonding technique succeeds, observed problems from oxide film $\left(\mathrm{A}_{2} \mathrm{O}_{3}\right)$ usually present on the metal surface. These oxides are barriers for atomic diffusion because the oxide has a high melting point. However, good surface preparation is essential for diffusion bonding method.

In the present work, an investigation of the joining parameters that affects microstructure and mechanical properties of dissimilar diffusion bonding joints of the SSM7075 and SSM356 aluminum alloys is conducted. After diffusion bonding, samples are put to test tensile strength, hardness, and examined microstructure by scanning electron microscopy.

\section{Experimental Procedures}

\subsection{Semi-Solid Metal Aluminum Alloys}

In experiments, we studied on SSM7075 and SSM356 aluminum alloys; both materials were formed by semi-solid casting technique (Gas Induced Semi Solid; GISS). The conditions of casting for SSM7075 aluminum alloys were temperature at $640^{\circ} \mathrm{C}$ and nitrogen gas flowing rate at 5 liters per minute through porous graphite for 10 seconds by the time at quenching, then squeeze casting. Likewise, conditions of casting for SSM356 aluminum alloys were temperature at $620^{\circ} \mathrm{C}$ and nitrogen gas flowing rate 5 liters per minute through porous graphite for 8 seconds by the time at quenching, before being squeeze casting. The chemical compositions for SSM7075 and SSM356 aluminum alloys are shown in Table 1.

Table 1. Chemical composition of aluminum 7075 and 356 alloy (Wt\%).

\begin{tabular}{ccccccccc}
\hline Materials & $\mathrm{Si}$ & $\mathrm{Fe}$ & $\mathrm{Cu}$ & $\mathrm{Mn}$ & $\mathrm{Mg}$ & $\mathrm{Zn}$ & $\mathrm{Ti}$ & $\mathrm{Al}$ \\
\hline 7075 & - & 0.46 & 1.93 & - & 2.50 & 6.08 & - & Bal. \\
\hline 356 & 7.74 & 0.57 & 0.05 & 0.06 & 0.32 & 0.01 & 0.05 & Bal. \\
\hline
\end{tabular}

After casting, base metals of both materials have globular grain structures shown in Fig.1. The microstructure of SSM7075 aluminum alloys includes aluminum matrix $(\alpha-\mathrm{Al})$ and eutectic phase $(\mathrm{MgZn} 2)$ shown in Fig. 1(a) with the grain size at 20-25 $\mu \mathrm{m}$. SSM356 aluminum alloys includes aluminum matrix ( $\alpha-$ $\mathrm{Al})$ and eutectic phase $\left(\mathrm{Mg}_{2} \mathrm{Si}\right)$ shown in Fig. 1(b) with the grain size at 19-22 $\mu \mathrm{m}$. 


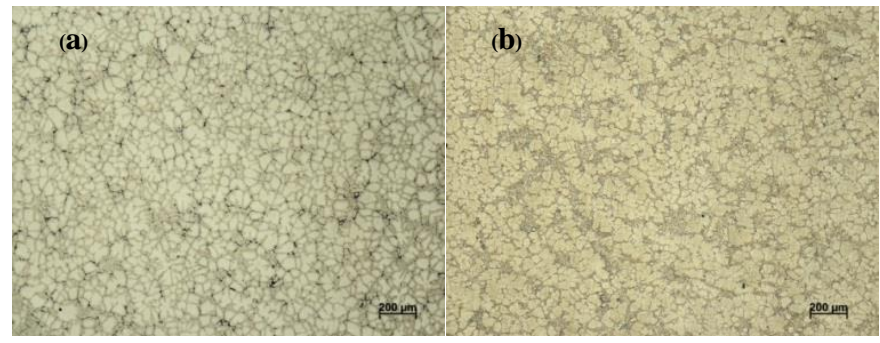

Fig. 1. Globular grain structure of SSM7075 and SSM356 aluminum alloys.

\subsection{Methods}

The sample preparation was carried out by tuning surfaces with lathe automatic machine. The samples are cylindrical in shape with $\varnothing 12 \times 45 \mathrm{~mm}$, of which the surface was only lathed without polishing by grinding with P180 grit SiC paper [12], and cleaned in acetone for 60 seconds. During diffusion bonding, the SSM356 sample is on the top side and SSM7075 aluminum alloy is on the bottom side of diffusion bonding with butt-welded joints. Bonding was performed in argon atmosphere at 4 liters per minute within a high temperature chamber attached to a testomatic-compression testing machine. The principle of diffusion bonding is shown in Fig. 2 and the joining parameters used for this experiments are summarized below:

1. Diffusion bonding temperature: $673,723,773$, and $823 \mathrm{~K}$

2. Contact pressure: $3 \mathrm{MPa}$

3. Heating holding time: 60 and 120 minutes.

After diffusion bonding, all samples are brought to be prepared for the surface with milling machine. Microstructure analysis was carried out by a light optical microscope (Olympus, model: BH2-UMA). The

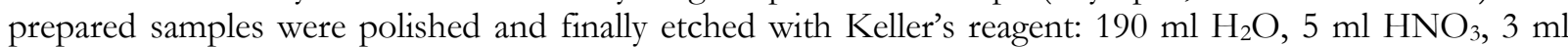
$\mathrm{HCl}$, and $2 \mathrm{ml} \mathrm{HF}$. The samples were etched for 5 seconds in order to study the grain structure of the weld zone and other areas. In order to verify the main bonding mechanism, diffusion analyses were carried out by scanning electron microscopy (SEM) with back-scattered electron image mode at the bonding interface on the central region of the samples. An electron microscope (FEI-Quanta, Japan; model: 400) was used, allocated in the Scientific Equipment Center, Prince of Songkla University, and Vickers hardness was measured by Zwick/Roell, model: ZHU.

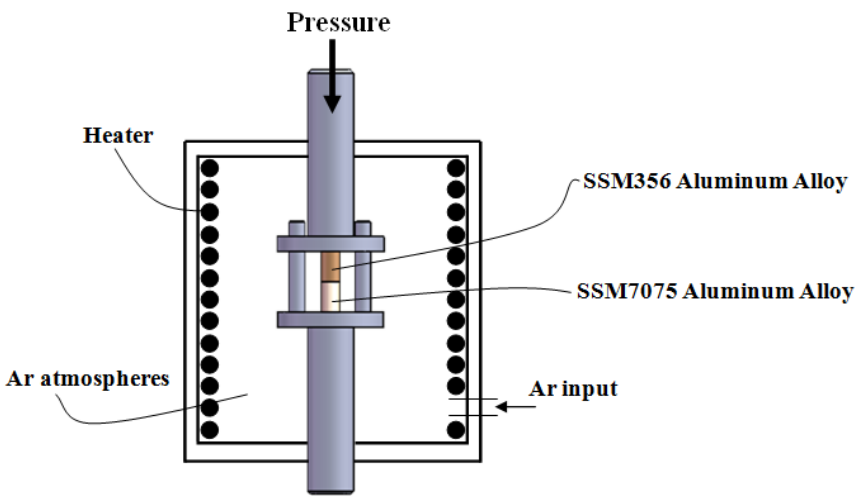

Fig. 2. Schematic drawing of diffusion bonding.

\section{Results and Discussion}

\subsection{Default Fonts}

Figure 3 shows the microstructure of the diffusion bond line with 60 minutes holding time. It was found that bond lines in the temperature of 673 and $723 \mathrm{~K}$ have elongated voids shown in Figs. 3(a)-(b), which 
they are parallel to the direction of the contact area. The reason of this incident may cause from both lower temperature and shorter holding time which induce elimination of incompleted voids. However, we have noticed that when temperature increases from 673 to $773 \mathrm{~K}$, it led to a decrease of the elongated voids shown in Fig. 3(c) because, at higher temperatures, the atoms get increasingly energy. Thus, higher the holding temperature used, faster the diffusion occurred due to that the diffusion coefficient generally increases with increasing the temperature, based on Fick's second law of diffusion as shown in Eq. (1).

$$
\frac{\partial c}{\partial t}=D \frac{\partial^{2} c}{\partial x^{2}}
$$

where $\partial \mathrm{c} / \partial \mathrm{t}$ is the change in the solute concentration with the time at a given position in the substrates, representing isothermal solidification rate, $D$ is the diffusion coefficient, and $\partial^{2} \mathrm{c} / \partial \mathrm{x}^{2}$ is the change in concentration gradient with distance [13]. However, unlike Figs. 3(a)-(c), the bonded line was nearly completed and found that elongated voids disappear. However, small amount of micro voids are presented shown in Fig. 3(d), which the temperature at $823 \mathrm{~K}$ is generally considered as a complete sound bond without a distinct bond line.
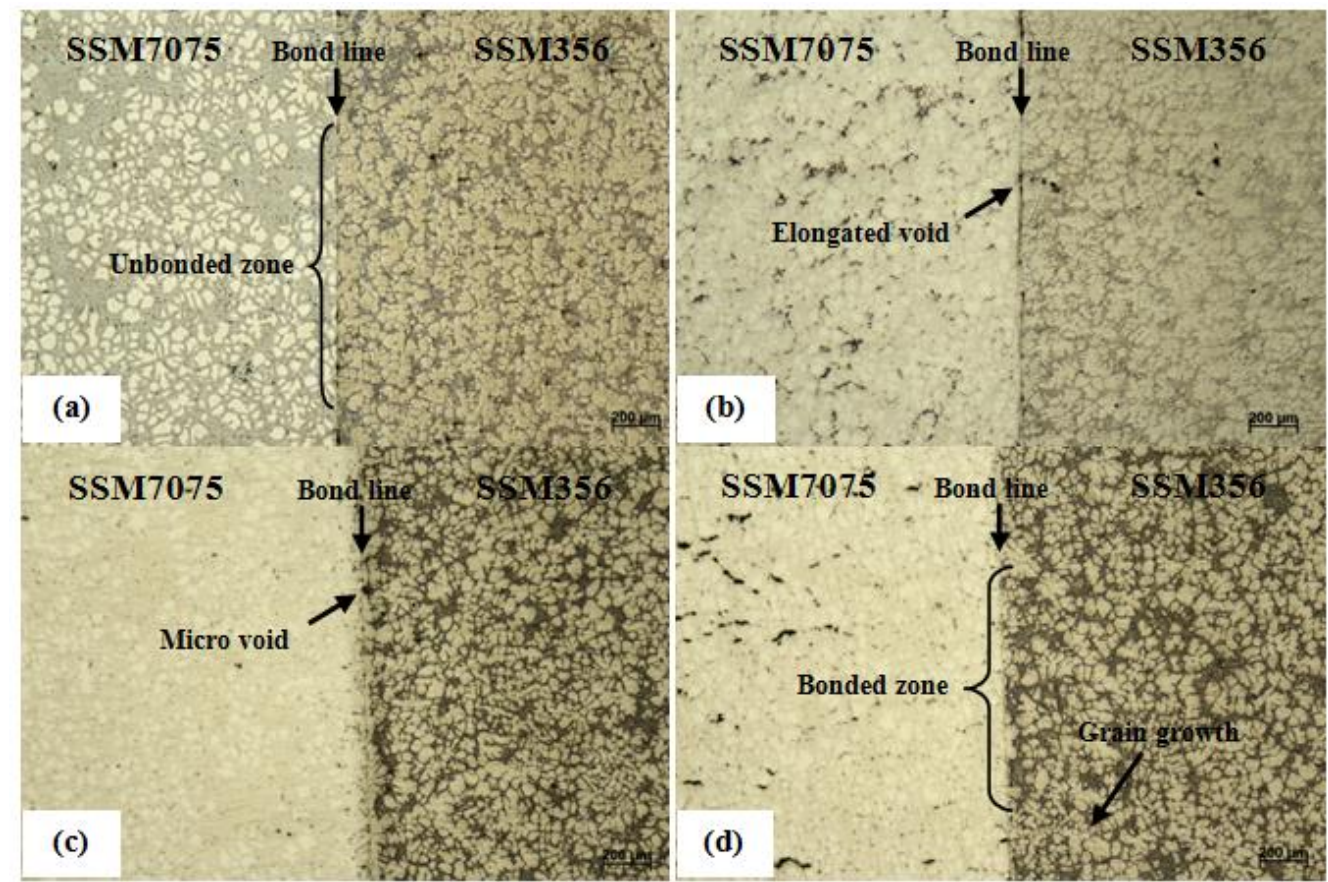

Fig. 3. Microstructure cross-sections in holding time 60 minutes of the joint bonded.

If the holding time is increased, adhesion between samples will become better. For example, during the temperature at $673 \mathrm{~K}$ and $723 \mathrm{~K}$ with 120 minutes holding time, it was found that elongated voids were eliminated; then, they turned into micro voids shown in Figs. 4(a)-(b). Likewise, when temperature increases from 773 to $823 \mathrm{~K}$, this eliminates the voids completely shown in Figs. 4(c)-(d). Micro voids remain very few which is often particularly soiled areas or contaminated areas. Although high temperature for welding makes the pieces adhere together, it causes growth of the grains [14]. Similarly, holding time excessively lead to slowly creep behaviour of grains. As a result, grains grow ( $\alpha$-phase) and small grains will diffuse to the larger grains until they lose their globular shape. For the temperature at $773 \mathrm{~K}$ and holding time 120 minutes, the SSM7075 aluminum alloy has grain-growth size around $28-34 \mu \mathrm{m}$, and SSM356 aluminum alloy has grain-growth size around 25-29 $\mu \mathrm{m}$ shown in Fig. 4(d). 


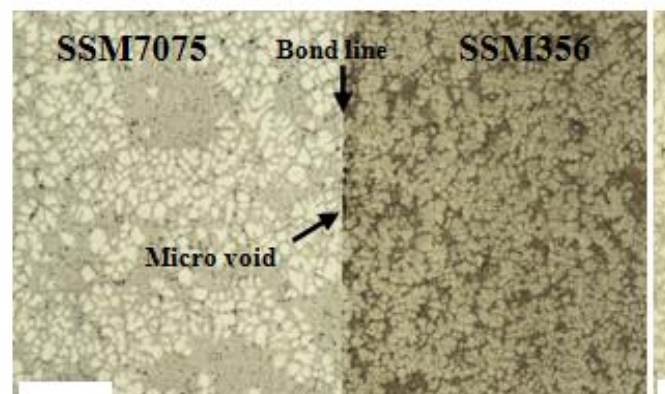

(a)
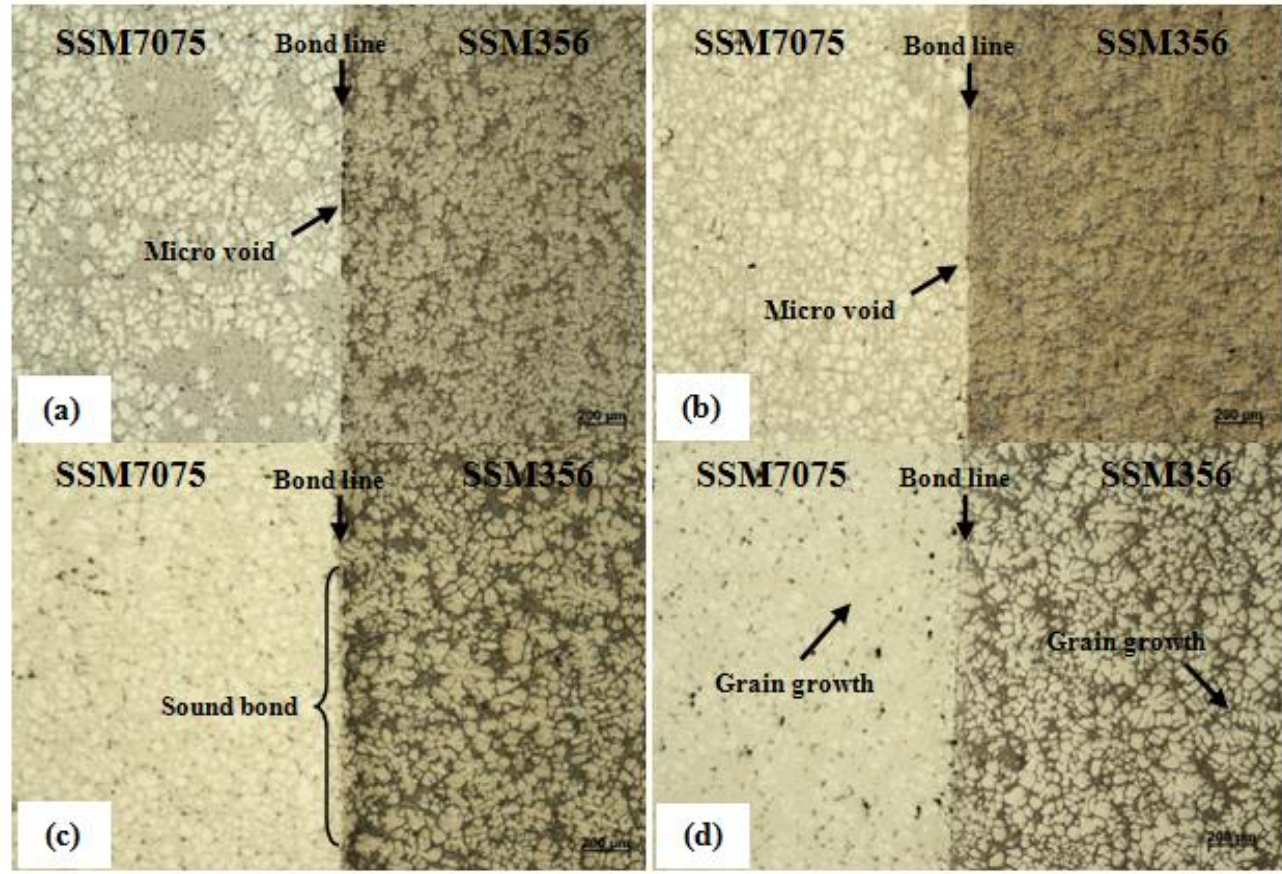

(b)

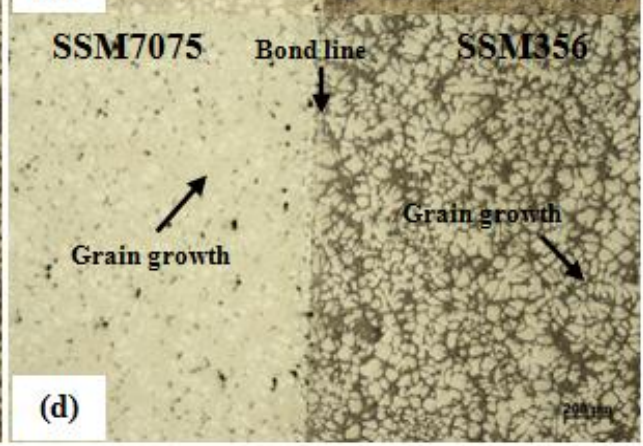

Fig. 4. Microstructure cross-sections in holding time 120 minutes of the joint bonded.

Figure 5 shows a micrographic overview in back-scattered electron image of the cross-section sample from scanning electron microscopy with magnification at $50 \mathrm{X}$ with the temperature at $773 \mathrm{~K}$, holding time 120 minutes, and contact pressure of $3 \mathrm{MPa}$. It can be seen that two materials were seemed to be bonded but they come across the void with very little volume. It is noteworthy that the micro void locating at the centre of the bonded line was obtained from the bonded interface because heat energy is normally transferred from the edge of the materials to the centre of bonded interface where the heat energy eventually reaches to eliminate voids. However, when the samples were inspected at 1000X and 2500X magnification, voids can be found and shown in Fig. 5(a)-(b). But, the size of the voids is very small. In experiments, the particle distribution was studied at various positions in the bonded line zone. The microstructure of the bonded line, taken at 1000X shown in Fig. 5(a) illustrates particle incorporation of $\mathrm{MgZn}_{2}$ phase in SSM7075 aluminum alloy. On the other hand, SSM356 aluminum alloy represents particle incorporation of $\mathrm{Mg}_{2} \mathrm{Si}$ phase; the temperature during diffusion influences repeated precipitation of $\mathrm{MgZn}_{2}$ and $\mathrm{Mg}_{2} \mathrm{Si}$ phase. Thus, only the recrystallization of the parent microstructure can be considered as a microstructural transformation caused by the thermal cycles [15]. Likewise, high temperature causes the movement of the particles from two materials resulting atomic diffusion because it can increase the diffusion rate. Moreover, thermal resulting precipitation of $\mathrm{MgZn}_{2}$ and $\mathrm{Mg}_{2} \mathrm{Si}$ phase after precipitation will make two phases have smaller particles shown in Fig. 5(b). It is good to note that SSM7075 aluminum alloy can easily become more soluble phase and flow into SSM356 aluminum alloy. The particles were born from the diffusion between them. At the same time, the particles of SSM7075 aluminum alloy are diffused to SSM356 aluminum alloy because particles of SSM7075 are smaller and more soluble than particles of SSM356 aluminum alloy. Finally, higher temperature was prone to make buckling and deformed samples after welding. 

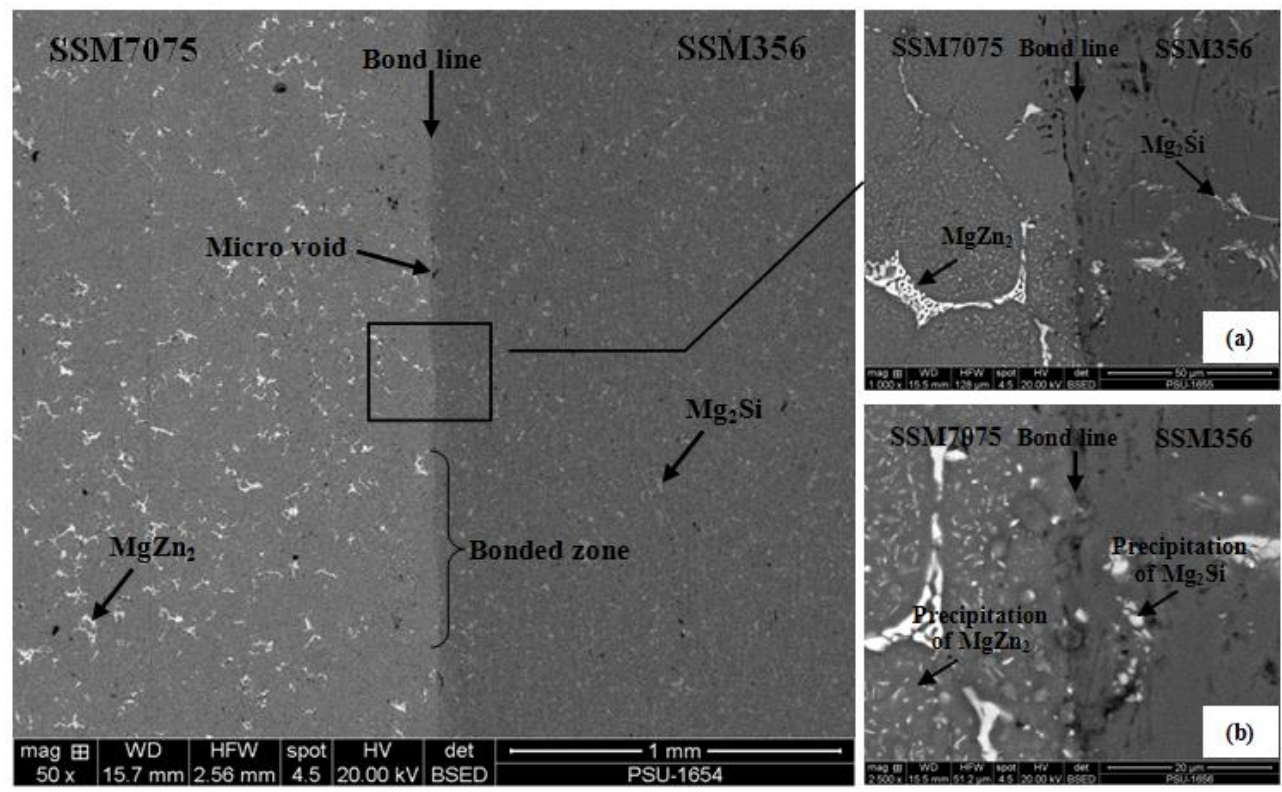

Fig. 5. Back-scattered electron image of the cross-section of the joint bonded.

\subsection{Diffusion Bonding of Particles in Bond Line}

The distributions of the Zinc ( $\mathrm{Zn})$, Silicon $(\mathrm{Si})$, Magnesium $(\mathrm{Mg})$ and Copper $(\mathrm{Cu})$, and Oxide $(\mathrm{O})$ particles were studied at various positions both in the bonded line zone and near bonded line. We used an imagemapping technique to analyse the distribution of the particles. Figure 6. shows the centre of the sample with temperature at $773 \mathrm{~K}, 120$ minutes holding time, and the contact pressure of $3 \mathrm{MPa}$. The results showed that there have diffusions of atoms between the two types of materials. Figure 6(a) shows aluminum matrix which is the basis of the two materials and Fig. 6(b) shows $\mathrm{Zn}$ particles in SSM7075 diffused to SSM356 aluminum alloy. Because Zn particles in SSM7075 aluminum alloy have higher concentrations; thus, it will diffuse to SSM356 aluminum alloy. Similarly, Cu particles in SSM7075 diffuse to SSM356 aluminum alloy shown in Fig. 6(e). On the contrary, Si particles in SSM356 diffuse to SSM7075 aluminum alloy shown in Fig. 6(c) because of the higher concentration of Si in SSM356 aluminum alloy. However, Mg particles in SSM7075 aluminum alloy diffuse less than other alloying elements shown in Fig. 6(d) because both SSM356 aluminum alloy and SSM7075 aluminum alloy already have Mg for 0.32 percent and 2.5 percent respectively. The eutectic phase distributing throughout the aluminum matrix was more when the temperature or time is increased [13]. Although these atoms are moving during high heat and proper length of time, diffusion rate of atoms also depends on the concentration of each element between two materials [14]. However, during diffusion bonding, it was found that oxygen occurred when it was not under vacuum condition shown in Fig. 6(f). This is the reason why oxide was distributed throughout in bonded line and near bonded line. The oxide that occurred during the welding process results a slower rate of diffusion [16]. Although oxide hinders diffusion bonding process of aluminum alloy, welding under an argon atmosphere can reduce the amount of oxide. The chemical compositions of the bonded line were examined by EDX technique. The experimental results showed bonded line that has aluminum matrix for 83.15 percent, which the value of secondary Si particles was 5.0 percent and some Si particles just diffuse together between SSM7075 and SSM356 aluminum alloy. The value of Mg particles diffusing between the two materials was less, around 3.1 percent, because two materials have $\mathrm{Mg}$ in the main ingredient.

Furthermore, $\mathrm{Zn}$ particles in SSM7075 aluminum alloy were found that they diffuse to SSM356 aluminum alloy and the value was 4.0 percent. However, the rate of diffusion depends on temperature and holding time. When high temperature and longer holding time were used, the rate of diffusion was faster. In contrast, when low temperature and short holding time were used, the rate of diffusion was slower. It is noteworthy that the value of oxide was 4.3 percent and these oxides layer occurred from the infiltration in the bonded line during welding [16]. 


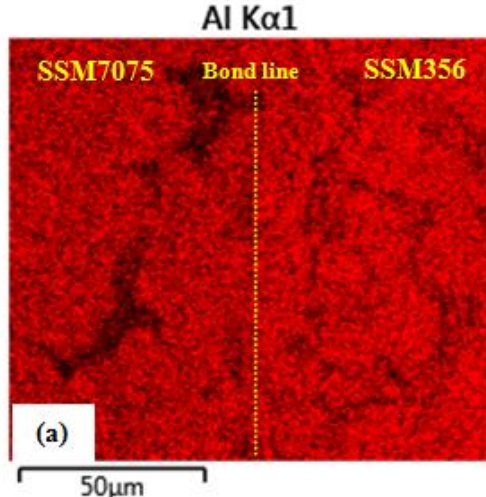

Si K $\alpha 1$

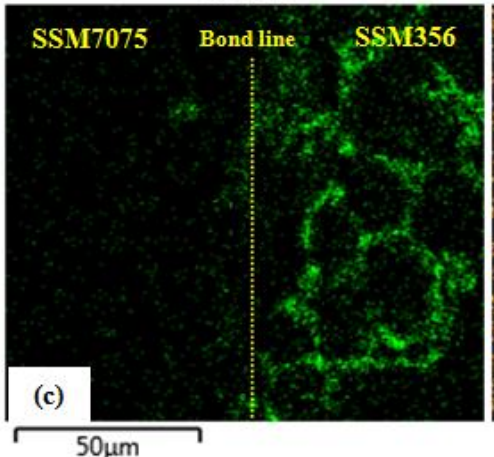

$\mathrm{Cu} \mathrm{K \alpha 1}$

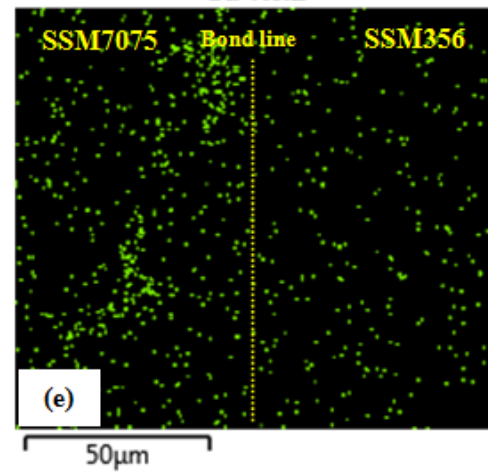

Zn Ka1

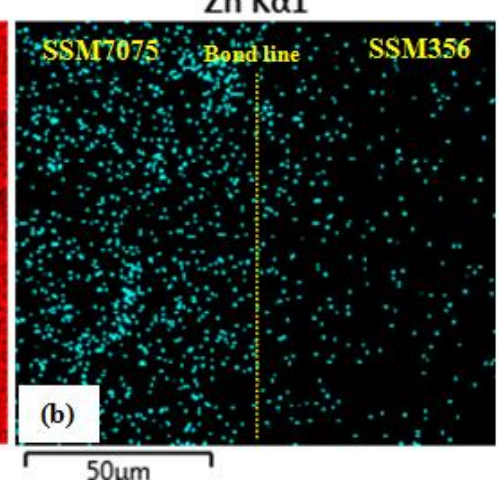

$\mathrm{Mg} \mathrm{K} \alpha 12$

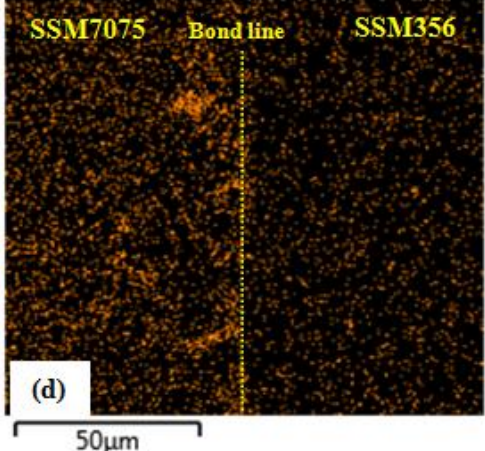

$\mathrm{O} K \alpha 1$

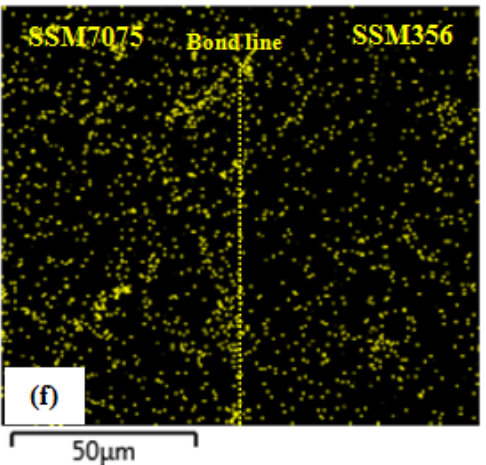

Fig. 6. Micrographic of mapping image of the cross-section of the joint bonded.

\subsection{Tensile Strength of Joint}

The tensile strength of the dissimilar joint of SSM7075 with SSM356 aluminum alloy is shown in Fig. 7. It was found that at temperature of $773 \mathrm{~K}$, holding time for 120 minutes, and the contact pressure of $3 \mathrm{MPa}$ provides maximum average tensile strength value which was $94.94 \mathrm{MPa}$. Therefore, joint efficiency of welded samples is around 56.48 percent when base material aluminum SSM356 is $168.09 \mathrm{MPa}$, and joint efficiency of welded samples is around 45.86 percent when base material aluminum SSM7075 is 207.08 $\mathrm{MPa}$. However, all samples are firmly attached at the bonded line in all conditions. The excessive longer time can reduce the tensile strength because of buckling distortion around the welded zone, but the very high temperature may also cause deformation of the sample after diffusion welding [16]. The equation used to calculate the joint efficiency is given as:

$$
\text { Joint efficiency }=\frac{\text { UTS of bonded samples } \times 100}{\text { UTS of base samples }}
$$


In contrast, the lower temperature and shorter time can reduce tensile strength due to elimination of the incompleted voids which represents the percentage of contact area. These voids and oxide layers are going to reduce tensile strength [17-18]. For example, at temperature of $673 \mathrm{~K}$ and holding time for 60 minutes, an average tensile strength value was $27.56 \mathrm{MPa}$. When increasing temperature from 723 to $823 \mathrm{~K}$, tensile strength also increases to $51.26,71.13$, and $69.44 \mathrm{MPa}$ respectively. It is noteworthy that, when time increases, tensile strength increases as well because the diffusion of atoms of the two materials has increased. Therefore, the right variables are important for the diffusion bonding.

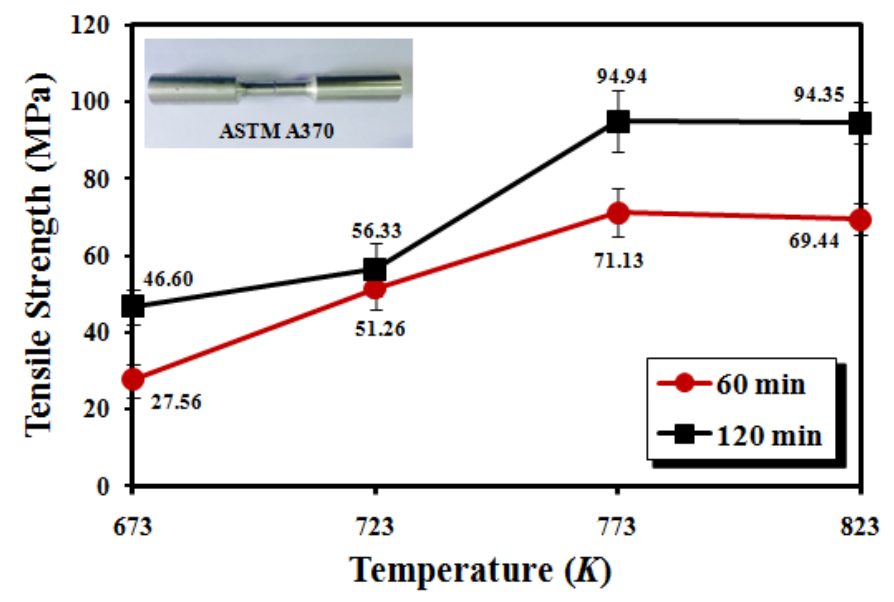

Fig. 7. Tensile strength of joint.

\subsection{Vickers Hardness}

Figure 8 shows microhardness profiles of hardness values from the welded middle section $(0.2 \mathrm{~mm}$ away from the bonded line). In all condition, the hardness values in all regions were higher than the hardness values of base materials (As cast) - base SSM356 aluminum alloy was 67.23 HV and SSM7075 aluminum alloy was $104.70 \mathrm{HV}$ - because heat during diffusion bonding led the eutectic phase of materials be precipitated [13]. This is similar to solution heat treatment process. Thus, only the recrystallization of the parent microstructures can be considered as a microstructural transformation caused by the thermal [19-20]. When the temperature is increased from 673 to $823 \mathrm{~K}$, hardness is also increased. Likewise, increasing holding time from 60 to 120 minutes, hardness is also increased. However, if time and temperature are too high, swelling and buckling after welding can be observed because eutectic phase will be changed to liquid. Figure 8(a) shows a condition with 60 minutes holding time. It was found that the side of the SSM7075 aluminum alloy with temperature at $823 \mathrm{~K}$ provides the maximum hardness value for $112.56 \mathrm{HV}$. In addition, for the side of the SSM356 aluminum alloy, it was found that the hardness values of all temperature are similar around $67.04 \mathrm{HV}$. However, when holding time is increased to 120 minutes shown in Fig. 8(b), the hardness value becomes higher, which temperature at $823 \mathrm{~K}$ creates the maximum hardness value for $121.20 \mathrm{HV}$. Moreover, the hardness value on the side of the SSM356 aluminum alloy was 73.53 HV and the hardness value in bonded line was $105.80 \mathrm{HV}$. Finally, diffusion bonding processes promoted hardness of the aluminum alloy after welded. 

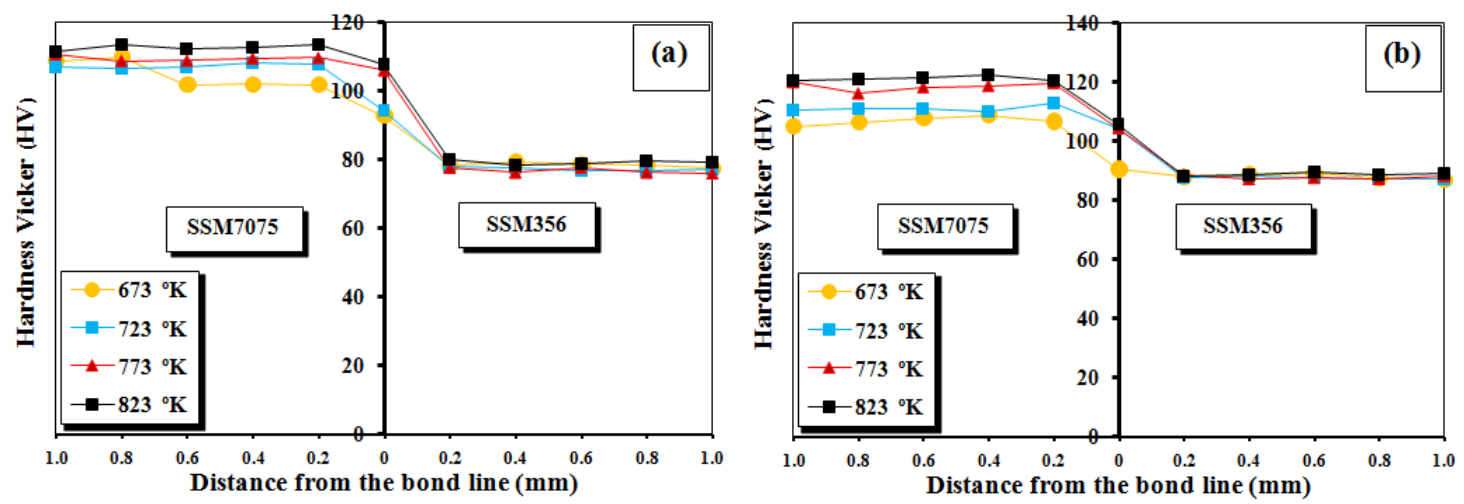

Fig. 8. Hardness profiles across the bonded line, (a) 60 minutes and (b) 120 minutes.

\section{Conclusions}

From this work, the diffusion bonding process for dissimilar SSM7075 with SSM356 aluminum alloy can be concluded that the diffusion bonding of the SSM7075 to SSM356 aluminum alloy are as follows:

1. The maximum average tensile strength value was $94.94 \mathrm{MPa}$ for the parameters with the temperature of $773 \mathrm{~K}$, holding time for 120 minutes, and the contact pressure of $3 \mathrm{MPa}$.

2. The microstructure after diffusion welding is globular structure which is the same as the original texture of the material. In addition, the formation of eutectic phases in bonded line consists of $\mathrm{Al}_{2} \mathrm{CuMg}, \mathrm{Mg}_{2} \mathrm{Si}$, and $\mathrm{Al}_{2} \mathrm{Mg}_{2} \mathrm{Zn}_{3}$ phases along the bond interface.

3. Vickers hardness value of the bonded line is $105.80 \mathrm{HV}$, the side of the SSM7075 was $121.20 \mathrm{HV}$, and the side of the SSM356 aluminum alloy was $73.53 \mathrm{HV}$, which higher than of base metal as a result of the heating.

\section{Acknowledgements}

This work was supported by the Songkhla Rajabhat University. Researchers thank the Department of Engineering, Faculty of Industrial Technology, Songkhla Rajabhat University and Department of Industrial Engineering, Faculty of Engineering, Rajamangala University of Technology Srivijaya University in Thailand, and especially Mr. Watchara Aunseam and Mr. Sirawit Juthong for their kind supports, is also appreciated.

\section{References}

[1] G. Govender, H. Moller, and O. F. R. A. Damm, "Semisolid Processes," Comprehensive Materials Processing, vol. 5, pp. 109-134, 2014.

[2] R. Burapa, S. Janudom, T. Chucheep, R. Canyook, and J. Wannasin, "Effects of primary phase morphology on mechanical properties of $\mathrm{Al}-\mathrm{Si}-\mathrm{Mg}-\mathrm{Fe}$ alloy in semi-solid slurry casting process," Transactions of Nonferrous Metals Society of China, vol. 20, pp. s857-s861, 2010.

[3] J. Wannasin, S. Janudom, T. Rattanochaikul, and M. C. Flemings, "Development of the gas induced semi-solid metal process for aluminum die casting applications," Solid State Phenom, vol. 141, pp. 97$102,2008$.

[4] T. Chucheep, R. Burapa, S. Janudom, S. Wisutmethangoon, and J. Wannasin, "Semi-solid gravity sand casting using gas induced semi-solid process," Transactions of Nonferrous Metals Society of China, vol. 20, pp. s981-s987, 2010.

[5] R. S. Mishra and Z. Y. Ma, "Friction stir welding and processing," Materials Science and Engineering R, vol. 50, no. 1, pp. 1-78, 2005.

[6] T. S. Srivatsan, V. Satish, and P. Lisa, "The tensile deformation and fracture behavior of friction stir welded aluminum alloy 2024," Materials Science and Engineering A, vol. 466, no. 1, pp. 235-245, 2007.

[7] M. N. Ahmad fauzi, M. B. Uday, H. Zuhailawati, and A. B. Ismail, "Microstructure and mechanical properties of alumina-6061 aluminum alloy joined by friction welding," Materials and Design, vol. 31, no. 2, pp. 670-676, 2010. 
[8] G. Mahendran, V. Balasubramanian, and T. Senthilvelan, "Influences of diffusion bonding process parameters on bond characteristics of $\mathrm{Mg}$-Cu dissimilar joints," Transactions of Nonferrous Metals Society of China, vol. 20, no. 6, pp. 997-1005, 2010.

[9] H. Nami, A. Halvaee, H. Adgi, and A. Hadian, "Microstructure and mechanical properties of diffusion bonded $\mathrm{Al} / \mathrm{Mg}_{2} \mathrm{Si}$ metal matrix in situ composite," Materials and Design, vol. 31, no. 8, pp. 3908-3914, 2010.

[10] Y. S. Cheng and X. H. Zhang, "Interfacial strength and structure of joining between 2024 aluminum alloy and SiCp/2024 Al composite in semi-solid state," Materials and Design, vol. 65, pp. 7-11, 2015.

[11] N. Masahashi and S. Hanada, "Effect of pressure application by HIP on microstructure evolution during diffusion bonding," Materials Transactions, vol. 46, no. 7, pp. 1651-1655, 2005.

[12] A. S. Zuruzi, H. Li, and G. Dong, "Effects of surface roughness on the diffusion bonding of Al alloy 6061 in air," Materials Science and Engineering A, vol. 270, no. 2, pp. 244-248, 1999.

[13] M. M. Atabaki and J. Idris, "Low-temperature partial transient liquid phase diffusion bonding of $\mathrm{Al} / \mathrm{Mg}_{2} \mathrm{Si}$ metal matrix composite to AZ91D using Al-based interlayer," Materials and Design, vol. 34, pp. 832-841, 2012.

[14] Y. E. Wu and Y. L. Lo, "Surface protection for AA8090 aluminum alloy by diffusion bonding," Theoretical and Applied Fracture Mechanics, vol. 38, no. 1, pp. 71-79, 2002.

[15] X. P. Zhang, L. Ye, Y. W. Mai, G. F. Quan, and W. Wei, "Investigation on diffusion bonding characteristics of $\mathrm{SiC}$ particulate reinforced aluminium metal matrix composites (Al/SiCp-MMC)," International Journal of Composites: Part A, vol. 30, no. 12, pp. 1415-1421, 1999.

[16] C. S. Lee, H. Li, and R. S. Chandel, "Vacuum-free diffusion bonding of aluminium metal matrix composite," Journal of Materials Processing Technology, vol. 89-90, pp. 326-330, 1999.

[17] K. Kitazono, A. Kitajima, E. Sato, J. Matsushita, and K. Kuribayashi, "Solid-state diffusion bonding of closed-cell aluminum foams," Materials Science and Engineering A, vol. 327, no. 2, pp. 128-132, 2002.

[18] D. R. Cooper and J. M. Allwood, "The influence of deformation conditions in solid-state aluminium welding processes on the resulting weld strength," Journal of Materials Processing Technology, vol. 214, no. 11, pp. 2576-2592, 2014.

[19] G. G. Sozhamannan and S. Balasivanandha Prabu, "Influence of interface compounds on interface bonding characteristics of aluminium and silicon carbide," Materials characterization, vol. 60, no. 9, pp. 986-990, 2009.

[20] Y. Huang, N. Ridley, F. J. Humphreys, and J. Z. Cui, "Diffusion bonding of superplastic 7075 aluminium alloy," Materials Science and Engineering A, vol. 226, no. 1, pp. 295-302, 1999. 